\title{
Contingent laws rule: Reply to Bird
}

DOI:

10.1093/analys/62.3.252

\section{Document Version}

Accepted author manuscript

Link to publication record in Manchester Research Explorer

\section{Citation for published version (APA):}

Beebee, H. (2002). Contingent laws rule: Reply to Bird. Analysis, 62(275), 252-255.

https://doi.org/10.1093/analys/62.3.252

\section{Published in:}

Analysis

\section{Citing this paper}

Please note that where the full-text provided on Manchester Research Explorer is the Author Accepted Manuscript or Proof version this may differ from the final Published version. If citing, it is advised that you check and use the publisher's definitive version.

\section{General rights}

Copyright and moral rights for the publications made accessible in the Research Explorer are retained by the authors and/or other copyright owners and it is a condition of accessing publications that users recognise and abide by the legal requirements associated with these rights.

\section{Takedown policy}

If you believe that this document breaches copyright please refer to the University of Manchester's Takedown Procedures [http://man.ac.uk/04Y6Bo] or contact uml.scholarlycommunications@manchester.ac.uk providing relevant details, so we can investigate your claim.

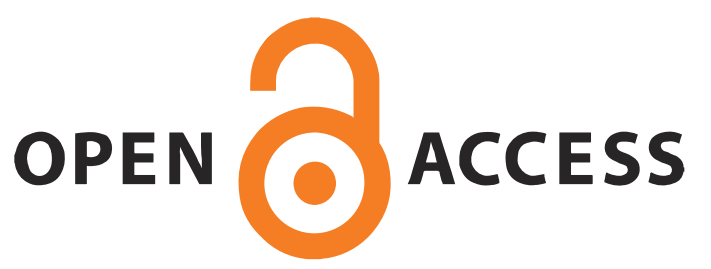


Contingent Laws Rule: Reply to Bird

\section{HELEN BEEBEE}

Please do not cite this version. The published version is:

Contingent Laws Rule: Reply to Bird', Analysis 62 (2002), 252-5

In a recent paper, Alexander Bird argues that the law that common salt dissolves in water is metaphysically necessary - and he does so without presupposing dispositionalism about properties. If his argument were sound, it would thus show that at least one law of nature is metaphysically necessary, and it would do so without illicitly presupposing a position (dispositionalism) that is already committed to a necessitarian view of laws. I shall argue that Bird's argument is unsuccessful.

Briefly, and omitting some subtleties that are not relevant to my purposes, Bird's argument runs as follows. A certain law of nature - Coulomb's law - needs to be true in order for salt to dissolve in water. But Coulomb's law also needs to be true in order for salt to exist at all. This is because

... the ionic character of salt is essential - any world in which there is salt is a world in which there exists an ionic bond. An ionic bond is, by definition, a bond that exists in virtue of the electrostatic attraction between ions. And electrostatic attraction is, necessarily, the force that exists between charged objects in virtue of Coulomb's law. Hence a world in which there is salt is a world in which Coulomb's law is true. (2001: 270-71)

Hence it is metaphysically necessary that salt dissolves in water, since any world where both salt and water exist must be a world where Coulomb's law is true; and at any world where salt and water exist and Coulomb's law is true, salt dissolves in water.

The problem with Bird's argument lies in his argument for the claim that 'a world in which there is salt is a world in which Coulomb's law is true' (271). I shall proceed by first 
presenting a verbal quibble, second, raising an unsuccessful but revealing objection to which Bird has a response, and, finally, presenting a counter-example - a world where salt exists but does not (always, or even often) dissolve in water - and offering a brief diagnosis.

First, the verbal quibble. Bird says, 'electrostatic attraction is, necessarily, the force that exists between charged objects in virtue of Coulomb's law' (271). I take it that he does not mean to say that in all worlds where Coulomb's law is false, there is no such thing as electrostatic attraction. Coulomb's law has the form ' $F=-\varepsilon_{0}\left(p q / r^{2}\right)$ where $\varepsilon_{0}$ is a constant and $F$ is the force between two charges whose values are $p$ and $q$ and whose separation is $r$ ' (271). Imagine a world $w_{l}$ where $\varepsilon_{0}$ takes a different (perhaps only very slightly different) value. Electrostatic attraction still exists at $w_{1}$ - it's just that force $F$ takes different values, given values of $p, q$ and $r$, to those it takes at the actual world given the same values of $p, q$ and $r$. It seems reasonable to think that this law is sufficiently similar to Coulomb's law for $F$ to count as electrostatic attraction.

So it isn't quite right to say that 'electrostatic attraction is, necessarily, the force that exists between charged objects in virtue of Coulomb's law'. Perhaps the right thing to say is that electrostatic attraction (at world $w_{i}$ ) is, necessarily, the force that exists (at $w_{i}$ ) between charged objects in virtue of some law or other that takes values of charges and separation as input and $\mathrm{F}$ as output - or something like that.

That's the verbal quibble out of the way. I'll now pretend to make an objection - one that won't work, and to which Bird himself provides a response - in order to set the scene for my actual objection. The pretend objection runs as follows. As we have just seen, the existence of electrostatic attraction (and hence the existence of ionic compounds) does not really require the truth of Coulomb's law. So there are worlds where salt exists and yet Coulomb's law is false. Hence, there are worlds where salt exists and yet fails to dissolve in water. Hence the law that salt dissolves in water is not metaphysically necessary.

The pretend objection is no good. All we have really shown so far is that the truth of Coulomb's law itself is not required for there to be electrostatic attraction and hence ionic compounds. But many worlds where there is electrostatic attraction will nonetheless be worlds where there is no salt. If we muck about with Coulomb's law too much, or perhaps in certain kinds of ways, we will find ourselves in worlds where the chemical bonding of sodium and chlorine ions results in a substance with quite different properties to salt (and 
hence in worlds where there is no salt). So only some - perhaps a very restricted class of alterations of Coulomb's law are compatible with the existence of salt. And there is no reason to think that such minor alterations will result in salt's failing to dissolve in water. As Bird says, 'a law that supports something very like the electrostatic behaviour of charged objects (as it occurs in this world) is a law that will ensure that something very like dissolving (as it occurs in this world) takes place' (272).

Having disposed of the bad objection, I now want to consider a possible world $w$ where Coulomb's law is not replaced by a similar law (similar enough for salt to exist there, and hence for salt to dissolve in water too). Instead, at $w$, Coulomb's law is replaced by a disjunctive law. The possible world in question is extremely strange, but I see no reason to suppose that it is not a possible world at all.

At world $w, F$ quite often $=-\varepsilon_{0}\left(p q / r^{2}\right)$, but not always. Moreover, there is no reason why (what is at the actual world) Coulomb's law fails in the cases where it fails. It isn't as if it always fails just on Thursday afternoons, or in temperatures above 30 degrees, or in any other particular kind of circumstance. It just sometimes fails. We can suppose, moreover, that when it does fail - just as a matter of fact, and for no particular reason $-F=-\varepsilon_{0}\left(p q / r^{4}\right)$ (say). At $w$, then, Coulomb's law is not a law, since it is not even true. Nonetheless, I claim, there is enough relevant regularity in $w$ for concepts like 'electrostatic attraction' and 'ionic bond' to be well defined. (Mostly, the electrostatic attraction between charges whose values are $p$ and $q$ and whose separation is $r$ is equal to $-\varepsilon_{0}\left(p q / r^{2}\right)$. But sometimes it's $-\varepsilon_{0}\left(p q / r^{4}\right)$.)

Granted that this is a coherent metaphysical possibility, it is a relatively straightforward matter to continue the story in such a way as to make 'salt dissolves in water' come out false. Suppose that, in fact, the ionic character of all lumps of salt at $w$ is exactly the same as that of actual lumps of salt. So salt at $w$ really does deserve to count as salt. But it just so happens that sometimes (or perhaps almost always), when one puts such a lump of salt into water, the electrostatic attraction exerted by the water dipoles on the sodium atoms is not such as to pull those atoms away from the salt crystal and into the water. (I have no idea whether or not $F=-\varepsilon_{0}\left(p q / r^{4}\right)$ will turn the trick, but something will.) So sometimes - almost always, if you like - salt fails to dissolve in water. So, at $w$, it is not true that salt dissolves in water. Hence it is not metaphysically necessary that salt dissolves in water. 
(Objection: the water dipoles are behaving in such a way as to make the watery stuff not really water at all. Response: It's just the relationship between the water dipoles and the sodium atoms that's not working according to Coulomb's law. The electrostatic attraction between the water molecules themselves at $w$ is just what it is in the actual world. There is no intrinsic difference between the watery stuff at $w$ and actual water. So $w$ 's watery stuff does indeed deserve to be called 'water'.)

The fault in Bird's argument is the assumption that other possible worlds work in a nice, orderly way. In particular, the argument assumes that for a law like Coulomb's law to be false at a world $w_{i}$, it has to be false in a nice, consistent, regular way. (Either it is false, but the replacement law at $w_{i}$ is close enough to Coulomb's law to maintain both the existence of salt and its solubility in water; or it is false and $w_{i}$ is different enough from the actual world for there to be no salt at all.)

However, we can grant that in order for there to be salt at a world $w_{i}$, the relationship between $p, q$ and $r$ must be one of a fairly small set of possible relationships (where the charges in question are charges of the sodium and chlorine ions that constitute the salt). And we can grant that in order for salt to dissolve in water, the relationship between $p, q$ and $r$ must be one of the very same small set of possible relationships (where the charges in question are the charges of the water dipoles and sodium atoms). But it does not follow that in any possible world where Coulomb's law (or something reasonably similar to it) is false, the two relationships (that is, the relationship between the sodium and chlorine ions on the one hand, and the relationship between the water dipoles and the sodium atoms on the other) fall together: the failure of just one of the relationships (the relationship between the water dipoles and the sodium atoms) is enough to make Coulomb's law (or something reasonably similar to it) false.

The world $w$ described above is, admittedly, a rather peculiar kind of world. But I see no reason to deny that it is a metaphysically possible world. One might wonder whether the disjunctive 'law' - either $F=-\varepsilon_{0}\left(p q / r^{2}\right)$ or $F=-\varepsilon_{0}\left(p q / r^{4}\right)$ - really deserves to be called a law. But that isn't to the point. $w$ is regular enough to contain genuine salt, yet irregular enough for salt (sometimes) to fail to dissolve in water. Whether or not the disjunction that correctly describes the behaviour of salt when dropped in water deserves to be called a law, $w$ is a possible world where 'salt dissolves in water' is false. 
University of Manchester

Manchester M13 9PL, UK

helen.beebee@man.ac.uk

\section{References}

Bird, A. 2001. Necessarily, salt dissolves in water. Analysis 61: 267-74. 